\title{
Low immunogenicity but reduced bioavailability of an interferon beta- I biosimilar compared with its biological parent: results of MATRIX, a cross-sectional, multicenter phase 4 study
}

\author{
This article was published in the following Dove Press journal: \\ Biosimilars \\ 15 September 2015 \\ Number of times this article has been viewed
}

\section{Carlos Cuevas' \\ Florian Deisenhammer ${ }^{2}$ \\ Xiaojun You ${ }^{3}$ \\ Mariano Scolnik ${ }^{4}$ \\ Regine Buffels ${ }^{3}$ \\ Bjørn Sperling 3 \\ Francisco Flores-Ramírez ${ }^{5}$ \\ Miguel Macías-Islas ${ }^{6}$ \\ Sergio Sauri-Suárez ${ }^{7}$ \\ On behalf of the MATRIX Investigator Group \\ 'Specialty Hospital, Department of Neurology, National Medical Center Siglo XXI, Mexican Institute of Social Security, Mexico City, Mexico; ${ }^{2}$ Department of Neurology, University of Innsbruck, Innsbruck, Austria; ${ }^{3}$ Biogen, Cambridge, MA, USA; ${ }^{4}$ Biogen, Argentina, Buenos Aires, Argentina; ${ }^{5}$ Department of Internal Medicine- Neurology, Hospital Regional ISSSTE Monterrey, Monterrey, ${ }^{6}$ University Center for Health Sciences, University of Guadalajara, Guadalajara, ${ }^{7}$ Internal Medicine/Department of Neurology, National Medical Center, Mexico City, Mexico}

Correspondence: Carlos Cuevas Hospital de Especialidades “Dr Bernardo Sepulveda G," Centro Médico Nacional Siglo XXI, IMSS, Av., Cuauhtémoc 330, Ier Piso, Colonia Doctores, Delegación Cuauhtémoc, CP 06720, Mexico City, Mexico Tel +52 5557610285

Email cacu6II52@hotmail.com
Abstract: MATRIX (Measuring neutralizing Antibodies in patients TReated with Interferon beta-1a IM in MeXico) was primarily a cross-sectional phase 4 study of patients with relapsing multiple sclerosis (RMS) that evaluated neutralizing antibody (NAb) frequency in Mexican and Colombian patients treated with intramuscular interferon (IFN) beta-1a in the form of Avonex ${ }^{\mathbb{R}}$ or the biosimilar drug Jumtab ${ }^{\circledR}$. A secondary long-term retrospective observational evaluation of safety, tolerability, and relapses was also performed for patients in each arm of the study. In the cross-sectional portion of the study, patients with multiple sclerosis who had been treated with once-weekly Avonex $(n=36)$ or Jumtab $(n=29)$ self-injections as their first and only diseasemodifying therapy for 1-3 years were retrospectively identified. The primary and secondary endpoints were proportion of patients with NAb levels $>100$ tenfold reduction units (TRU) and $>20$ TRU. The biological response to IFN beta-1a injections was assessed by change in serum neopterin levels and by pre- versus post-dose concentration difference. Safety, tolerability, and relapse-related information were also retrospectively assessed. No patients developed NAb levels $>100$ TRU. Neopterin levels were significantly higher relative to baseline with Avonex than with Jumtab. Supporting this result, flu-like symptoms were reported in a greater proportion of Avonex-treated than Jumtab-treated patients. No unexpected adverse events or significant differences in relapses were observed. In conclusion, Avonex and Jumtab exhibited minimal immunogenicity; Jumtab was associated with significantly lower neopterin activation and flu-like symptom frequency compared with Avonex, suggesting less IFN bioactivity with Jumtab.

Keywords: multiple sclerosis, neutralizing antibodies, flu-like symptoms, neopterin, follow-on biologics, biosimilars

\section{Introduction}

Intramuscular interferon (IFN) beta-1a was first approved for the treatment of relapsing multiple sclerosis (RMS) in 1996, and it has proved effective in reducing relapse rate and disability progression in patients with RMS. ${ }^{1,2}$ Over the past decade, multiple IFN beta-1a biosimilar formulations have been approved to treat RMS, although none have been approved as disease-modifying therapies for RMS in either the European Union or the United States. Currently, over ten different IFN beta-1a biosimilar formulations have been developed and approved to treat RMS in at least ten Asian and Latin American countries. ${ }^{3}$ IFN beta-1a biosimilars can vary from their reference proteins by virtue of the cell type in which the proteins are synthesized as well as in the final purification steps. ${ }^{4-6}$ Given the biological complexity of these potential differences, 
the possibility that small changes in protein structure can have dramatic effects on the immunogenicity of such proteins, including the production of neutralizing antibodies (NAbs), is a particular concern. Similarly, these steps may lead to changes in the stability of the protein and the level of aggregation.

The path to approval for biosimilars varies by region, and controlled studies are not always required for biosimilar drug approval or may be of too short a duration to assess the impact of differences in immunogenicity. ${ }^{5}$ The lack of these validation studies presents a potential safety issue because NAbs can reduce IFN beta-1a activity, resulting in a diminished clinical response to all IFNs. Thus there is a growing consensus that biosimilar products should be evaluated to determine if they have equivalent immunogenicity, safety, and efficacy to the reference compound..$^{7-9}$

Although European Union regulators recently announced that magnetic resonance imaging (MRI)-based variables may be used for evaluating biosimilars, ${ }^{10,11}$ assessing the clinical efficacy of IFN beta-1a-based therapeutics can be difficult because of the relatively low incidence of relapses, even in placebo-treated RMS patients. For this reason, a variety of biomarkers, including the metabolic factor neopterin, beta2-microglobulin, and 2'-5'-oligoadenylate synthetase, are routinely used to determine IFN bioactivity. ${ }^{12}$ While such biomarkers are not useful measurements of efficacy, they are appropriate for measurements of biological activity. Measuring serum concentrations of neopterin is a common method of assessing IFN beta-1a biological and pharmacodynamic activity. ${ }^{13}$ A patient's steady-state serum neopterin concentration is generally elevated while the patient is on IFN beta-1a therapy and typically increases following each IFN beta-1a injection. ${ }^{14}$ Thus, it is important to monitor both steady-state neopterin levels and the change induced by a given dose to assess the efficacy of an IFN beta-1a therapy.

The intramuscular IFN beta-1a formulation Avonex ${ }^{\circledR}$ (Biogen, Cambridge, MA, USA) elicits low immunogenicity, with a persistent $\mathrm{NAb}$ rate of $2 \%-8 \%,{ }^{15-17}$ whereas the immunogenicity of the biosimilar drug Jumtab ${ }^{\circledR}$ (Probiomed, Miguel Hidalgo, Mexico), approved to treat RMS in Mexico, Colombia, and Peru, is unknown. This study was designed to directly compare Avonex and Jumtab, focusing on the incidence of NAbs.

\section{Methods}

MATRIX (Measuring neutralizing Antibodies in patients TReated with Interferon beta-1a IM in MeXico; Clinical Trial NCT01556685) was a multicenter, cross-sectional, retrospective, observational study conducted in Mexico and Colombia. The study protocol included up to 180 retrospectively identified patients (90 per group) who had been treated with either Avonex or Jumtab as their first and only disease-modifying therapy for multiple sclerosis (MS) for 1-3 years, ie, the time when peak antibody titers in NAbpositive individuals are expected. All patients followed the same dosing schedule of once-weekly self-injection. Patients who had previously been treated with immunosuppressive therapy were excluded. There were no limitations on age, Expanded Disability Status Scale (EDSS) score, or other disease parameters as a condition for patient enrollment. The study protocol and informed consent forms were approved by the appropriate institutional review board for each site, and all patients provided written informed consent before entering the study.

The primary endpoint was the frequency of NAb levels $>100$ tenfold reduction units (TRU) in patients treated exclusively with either Avonex or Jumtab. Secondary endpoints included changes in neopterin levels as a proxy assessment of efficacy and additional measures of safety and tolerability over a 2-year time course, including the frequency of NAb levels $>20$ TRU and of flu-like symptoms.

The development of NAbs and neopterin induction were assessed in a cross-sectional analysis performed at a subset of preselected study sites. Patient blood samples were collected before IFN beta-1a injection and then sent to a central laboratory for analysis using a commercial luciferase assay. ${ }^{18}$ Possible relationships between patient NAb status and drug tolerability/safety were evaluated through a retrospective patient record review by investigators blinded to the patients' therapy. The immunogenicity rate was predetermined to be based on a single assessment and did not require persistence to be deemed positive. NAb levels $>100$ TRU were considered positive for the primary endpoint evaluation; NAb levels $>20$ TRU were considered positive for the secondary endpoint evaluation. At a select number of sites, patient blood samples were also collected 48-72 hours post-dose for analysis. The biological response to IFN beta-1a injections was assessed by mean percentage change in serum neopterin levels and by mean pre- versus post-dose concentration difference. Neopterin serum concentrations were measured using a competitive binding enzyme immunoassay (MP Biomedical, Solon, $\mathrm{OH}, \mathrm{USA}$ ), with a quantitation range of $0.906-101 \mathrm{ng} / \mathrm{mL}$ and assay precision (percentage coefficients of variability of assay controls) of $8.4 \%-13.3 \%$. Safety was assessed by adverse events collected during treatment. Relapses and associated outcomes were assessed 
based on retrospective review of patient records from 1 to 3 years prior to study enrollment. Summary statistics for relapse-associated outcomes were calculated as the total number of relapses, days of hospitalization, or duration of corticosteroid treatment reported divided by the number of patients reporting the outcome.

Data are presented as mean (standard deviation [SD]) and median (range). The Wilcoxon rank sum test was used to determine significance for paired data (not normally distributed), a chi-square test was used for analyses of categorical data, and two-tailed $t$-tests were used for normally distributed, continuous data.

\section{Results}

\section{Patients}

This study aimed to enroll a total of 180 patients ( 90 per treatment group). However, a number of external factors in both Mexico and Colombia limited study enrollment, including national government policies dictating pharmacy substitution of branded medications with locally produced biosimilars (Mexico) and the lack of availability of study medications at some local pharmacies. In addition, the inability to confirm that all patients had been treated with only one formulation over the 3-year duration of the study reduced enrollment. Final enrollment was limited to 65 patients whose entire treatment history could be confirmed: 36 patients treated exclusively with Avonex and 29 treated exclusively with Jumtab. The effect of this reduced enrollment on the statistical interpretation of the study results should be considered in subsequent data analysis and is discussed later.

The two patient populations were similar, with the exception that patients on Avonex therapy were significantly younger than those on Jumtab (mean [SD]: 37.1 [9.2] versus 44.6 [11.5] years; $P=0.005$; Table 1 ). In addition, despite having been diagnosed more recently ( 1.3 versus 2.9 years earlier; $P=0.082$ ), patients in the Avonex group tended to have a higher mean baseline EDSS score (2.2 versus 1.5; $P=0.106$ ). The duration (SD) of IFN beta- 1 a therapy was 24.5 (7.5) months for Avonex and 22.1 (8.1) months for Jumtab $(P=0.214)$. There were no differences between treatment groups in either the time from the first documented clinical event to the start of therapy or the time from the diagnosis of clinically definite MS to the start of IFN beta-1a therapy.

\section{Biomarkers}

$\mathrm{NAb}$ levels were obtained in 36 Avonex-treated and 29 Jumtab-treated patients. No patients developed NAb levels $>100$ TRU, and levels of $>20-100$ TRU were
Table I Patient demographics

\begin{tabular}{|c|c|c|c|}
\hline & Avonex $^{\circledR}$ & Jumtab $^{\circledast}$ & $P$-value \\
\hline Number of patients & 36 & 29 & \\
\hline Mexico & 28 & 29 & $0.007^{\mathrm{a}}$ \\
\hline Colombia & 8 & 0 & \\
\hline Sex (\% female) & 69 & 76 & $0.565^{\mathrm{b}}$ \\
\hline Age (years, mean $[S D]$ ) & 37.1 (9.2) & $44.6($ (II.5) & $0.005^{c}$ \\
\hline \multicolumn{4}{|c|}{ Time since MS diagnosis (years) } \\
\hline Mean (SD) & I.3 (2.9) & $2.9(4.6)$ & $0.082^{\mathrm{d}}$ \\
\hline Median (range) & $0.2(0-12.9)$ & $0.7(0-19.2)$ & \\
\hline \multicolumn{4}{|l|}{ Baseline EDSS score } \\
\hline Mean (SD) & $2.2(1.6)$ & $\mathrm{I} .5(\mathrm{I} .0)$ & $0.106^{\mathrm{d}}$ \\
\hline Median (range) & $2.0(0-6.0)$ & $1.0(0-4.0)$ & \\
\hline \multicolumn{4}{|c|}{ IFN beta-Ia treatment duration (months) } \\
\hline Mean (SD) & $24.5(7.5)$ & $22.1(8.1)$ & $0.214^{c}$ \\
\hline Median (range) & $22.5(11.9-37.4)$ & $20.2(12.3-37.3)$ & \\
\hline
\end{tabular}

Notes: aCalculated by Fisher's exact test, representing the difference between the proportion of patients on Avonex in Mexico and the proportion on Avonex in Colombia; ${ }^{b}$ chi-square test; 'two-sample $t$-test; ${ }^{d}$ Wilcoxon rank sum test.

Abbreviations: EDSS, Expanded Disability Status Scale; IFN, interferon; MS, multiple sclerosis; SD, standard deviation.

detected in one patient from each treatment group (Table 2). Neopterin levels were obtained in eight Avonex-treated and 18 Jumtab-treated patients. While the mean (SD) preinjection neopterin levels for Avonex (5.5 [3.9] nmol/L) and Jumtab (2.6 [1.6] nmol/L) were consistent with levels seen in apparently healthy individuals (mean [SD], 5.34 [2.74] nmol/L; range, $1.0-33.6 \mathrm{nmol} / \mathrm{L})^{19}$ for both groups, following treatment, mean neopterin levels for the Avonex group rose consistently and approached the upper limit of the $95 \%$ confidence interval for the normal population $(8.7 \mathrm{nmol} / \mathrm{L}){ }^{19}$ while those for Jumtab patients remained statistically indistinguishable from pre-dose values (Table 2). When the absolute change in neopterin levels was measured, the mean (SD) value for the Avonex-treated patients increased by $2.4(2.2) \mathrm{nmol} / \mathrm{L}$, while that for the Jumtabtreated patients increased by $0.7(1.2) \mathrm{nmol} / \mathrm{L}(P=0.008)$. Moreover, the mean values shown in Figure 1 are skewed

Table 2 NAb detection and neopterin concentration changes

\begin{tabular}{|c|c|c|}
\hline & Avonex $^{\circledR}$ & Jumtab $^{\circledR}$ \\
\hline \multicolumn{3}{|l|}{ NAbs, n (\%) } \\
\hline $\mathrm{n}$ & 36 & 29 \\
\hline$>100 \mathrm{TRU}$ & 0 & 0 \\
\hline$>20-100$ TRU & $\mathrm{I}(2.9)$ & $\mathrm{I}(3.4)$ \\
\hline \multicolumn{3}{|l|}{ Neopterin concentration } \\
\hline $\mathrm{n}$ & 8 & 18 \\
\hline Pre-dose (nmol/L, mean [SD]) & $5.5(3.9)$ & $2.6(1.6)$ \\
\hline Range & $2.0-13.7$ & $1.3-7$ \\
\hline 48-72 hours post-dose (nmol/L, mean [SD]) & $7.9(4.6)$ & $3.3(2.3)$ \\
\hline Range & $3.8-17.9$ & $1.4-11.5$ \\
\hline Percentage change (mean) & 43.6 & 29.6 \\
\hline
\end{tabular}

Abbreviations: NAb, neutralizing antibody; SD, standard deviation; TRU, tenfold reduction units. 


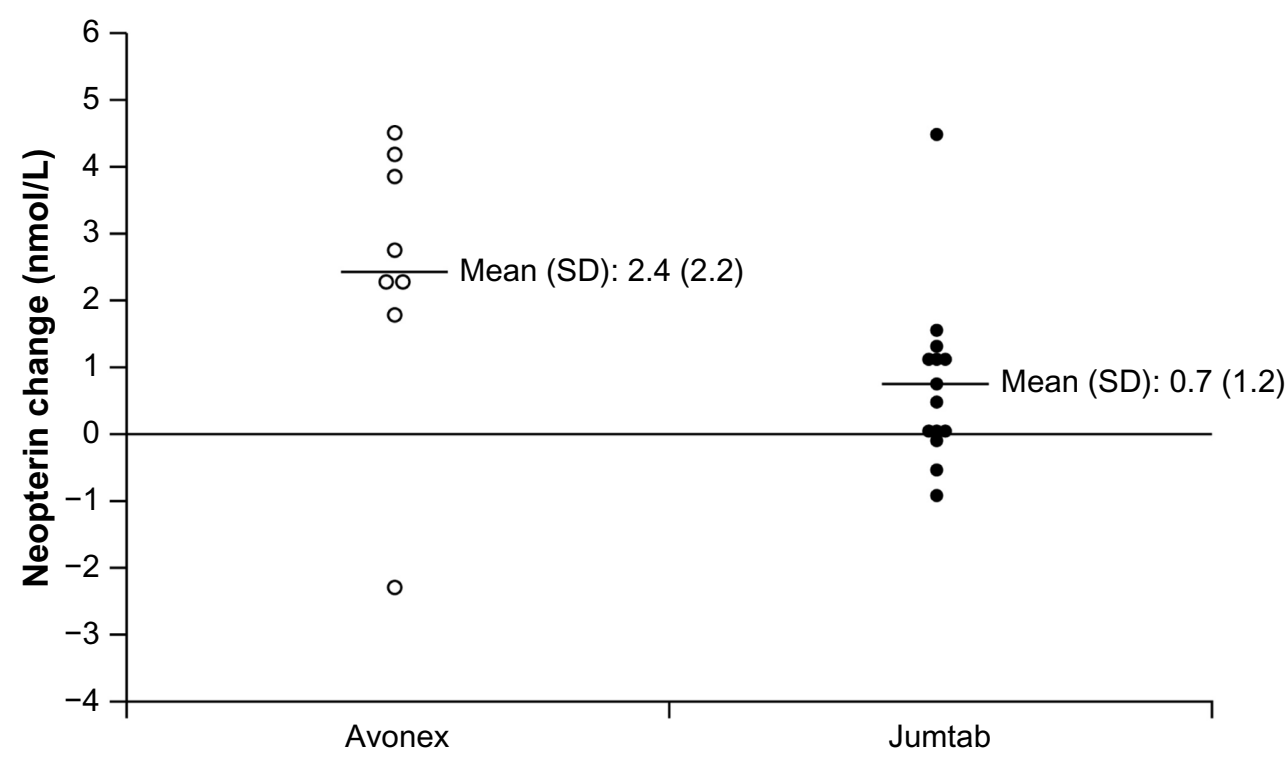

Figure I Change in serum neopterin concentration (pre-dose to 48-72 hours post-dose).

Notes: Levels seen in apparently healthy individuals were as follows: mean (SD), 5.34 (2.74) nmol/L; range, I.0-33.6 nmol/L. The upper limit of the $95 \%$ confidence interval for the apparently healthy population was $8.7 \mathrm{nmol} / \mathrm{L} .^{19}$

Abbreviation: SD, standard deviation.

in opposite directions by outliers in both patient groups, indicating the presence of individuals showing marked differences in their response to the therapy. This difference is also reflected in the percentage changes in neopterin levels; neopterin concentrations in the Avonex and Jumtab groups increased by $43.6 \%$ and $29.6 \%$, respectively, from pre-dose to $48-72$ hours post-dose (Table $2 ; P=0.0087$ ).

\section{Adverse events}

The most common adverse event for both formulations was the presence of flu-like symptoms, reported by $80.6 \%$ and $31.0 \%$ of Avonex- and Jumtab-treated patients, respectively $(P=0.0004)$. In patients treated with Avonex, other adverse events reported by more than one patient included injectionsite reactions $(n=5)$ and liver function abnormalities $(n=2)$. The only adverse events seen with Jumtab other than flu-like symptoms were injection-site reactions and headache, which were reported by two patients each (Table 3).

\section{Relapses}

The results of a retrospective patient record review of MS relapses showed no significant differences between groups for any of the relapse-related endpoints, including the number of relapses, number of patients reporting relapses, duration of hospitalization per relapse, total duration of hospitalization per patient, duration of corticosteroid use per relapse, and total duration of corticosteroid use per patient (Table 4).

\section{Discussion}

As the number of follow-on biologics being developed increases, it is critical to validate both the efficacy and safety of these new formulations, given the complexity of their manufacture and the risks presented by NAb formation. ${ }^{3,8}$ The MATRIX study was designed to provide a direct comparison between Avonex and a biosimilar, with a focus on assessing product safety in addition to measuring serum neopterin as a surrogate marker for immune activation.

Table 3 Adverse events

\begin{tabular}{|c|c|c|c|c|}
\hline \multirow[t]{2}{*}{$\begin{array}{l}\text { Patients reporting } \\
\text { adverse events, } \\
\text { n (\%) }\end{array}$} & \multicolumn{2}{|c|}{ Total patients } & \multicolumn{2}{|c|}{$\begin{array}{l}\text { Patients assessed } \\
\text { for neopterin } \\
\text { induction }\end{array}$} \\
\hline & $\begin{array}{l}\text { Avonex }^{\circledR} \\
(n=36)\end{array}$ & $\begin{array}{l}\text { Jumtab }^{\circledast} \\
(n=29)\end{array}$ & $\begin{array}{l}\text { Avonex }^{\circledR} \\
(\mathrm{n}=8)\end{array}$ & $\begin{array}{l}\text { Jumtab }^{\circledast} \\
(n=18)\end{array}$ \\
\hline Flu-like symptoms & $29(80.6)$ & $9(31.0)$ & $8(100)$ & $4(22.2)$ \\
\hline Injection site reactions & $5(13.9)$ & $2(6.9)$ & 0 & I (5.5) \\
\hline Headache & I (3.2) & $2(6.9)$ & 0 & $2(11.1)$ \\
\hline $\begin{array}{l}\text { Liver function } \\
\text { abnormalities }\end{array}$ & $2(6.5)$ & 0 & 0 & 0 \\
\hline Arthralgias & I (2.8) & 0 & 0 & 0 \\
\hline Depression & I (2.8) & 0 & 0 & 0 \\
\hline Dizziness & $\mathrm{I}(2.8)$ & 0 & I (I2.5) & 0 \\
\hline Fever & I $(2.8)$ & 0 & 0 & 0 \\
\hline Myalgias & I (2.8) & 0 & 0 & 0 \\
\hline Numbness & I (2.8) & 0 & $\mathrm{I}(12.5)$ & 0 \\
\hline Visual disturbance & $\mathrm{I}(2.8)$ & 0 & 0 & 0 \\
\hline
\end{tabular}

Notes: ${ }^{a} P=0.0004$ for difference in overall adverse event incidence between Avonex and Jumtab by chi-square test; ' five Avonex patients and 16 Jumtab patients did not report adverse events. 
Table 4 Summary of relapse-associated outcomes

\begin{tabular}{|c|c|c|c|}
\hline & $\begin{array}{l}\text { Avonex }^{\circledR} \\
(n=36)\end{array}$ & $\begin{array}{l}\text { Jumtab }^{\circledR} \\
(n=29)\end{array}$ & $P$-value ${ }^{a}$ \\
\hline Subjects reporting relapses, $\mathrm{n}$ & 16 & 8 & 0.165 \\
\hline $\begin{array}{l}\text { Mean number of relapses per } \\
\text { subject (SD) }\end{array}$ & $1.9(0.85)$ & $\mathrm{I} .4(0.74)$ & 0.127 \\
\hline Subjects hospitalized, $\mathrm{n}$ & 8 & 3 & 0.204 \\
\hline $\begin{array}{l}\text { Mean duration of hospitalization } \\
\text { per subject (days [SD]) }\end{array}$ & $9.4(3.64)$ & $8.3(6.11)$ & 0.727 \\
\hline Subjects with corticosteroids & 14 & 5 & 0.056 \\
\hline $\begin{array}{l}\text { Mean duration of corticosteroids } \\
\text { per subject (days }[S D])^{b}\end{array}$ & $7.8(3.43)$ & $7.6(4.88)$ & 0.911 \\
\hline
\end{tabular}

Notes: aChi-square test used for categorical data, two-sample $t$-test for continuous data; bduration of corticosteroids available for 12 Avonex patients and five Jumtab patients.

Abbreviation: SD, standard deviation.

The presence of NAbs has been associated with a more rapid progression of disability in RMS patients, a higher relapse rate, and an increase in the number of gadoliniumenhancing lesions on MRI. ${ }^{20}$ These data indicate that the clinical efficacy of IFN beta-1a may depend on the absence of NAbs, and the degree of NAb induction is therefore an important aspect of a given drug's safety profile. Product heterogeneity is a known risk for the development of NAbs. ${ }^{3}$ However, the relative risk of NAbs with Jumtab could not be addressed in this study because of the very low incidence of NAb induction for either IFN beta-1a formulation, compounded by the small number of patients that could be included in the final analysis.

MATRIX study enrollment was limited because of institutionally directed medication substitution at the pharmacy level, medication substitution based on local availability, and the resulting difficulty in verifying that all patients included in the study had been treated with a single IFN beta-1a formulation. Because of these enrollment concerns, the data here should be viewed as providing preliminary insights into the biological distinctions between these two compounds rather than offering definitive conclusions about the safety and efficacy of Jumtab versus Avonex. Further studies with substantially larger sample sizes are needed to conclusively establish the risk of developing NAbs subsequent to treatment with biosimilar IFN beta-1a.

Despite the low patient numbers, several important differences were seen in the biological activity of these two formulations. A secondary endpoint of the MATRIX study was to evaluate potential differences in the IFN biological activity of Jumtab relative to Avonex, using neopterin induction as a marker. ${ }^{13,19}$ Avonex but not Jumtab therapy was associated with robust elevations in neopterin levels, indicating significantly lower IFN biological activity with the biosimilar despite the amino acid homology between the products. It was also notable that baseline neopterin levels were higher in the Avonex-treated group, suggesting a consistent elevation of this biomarker due to IFN beta-1a activity. While these differences were not significant because of the low cohort sizes and the presence of outliers (Table 2), they confirm prior studies demonstrating that Avonex is able to induce a robust biological response in most patients, ${ }^{1,2}$ whereas this effect is less reliable for Jumtab. Neopterin levels in patients treated with Jumtab were lower, and may have been more likely to be suppressed than those in Avonex-treated cases, likely due to the low levels of active drug in the preparation. It is possible that the single Avonex-treated patient in whom suppression of neopterin induction was observed either did not inject the treatment or - due to natural variation in biological response - this patient's neopterin levels may simply be on the lower end of the expected range.

The differences in biomarkers cannot be attributed simply to the characteristics of the patient population. With the exception of the significantly younger age of the Avonextreated group and their somewhat higher EDSS score, there were no differences between the Avonex and Jumtab groups either in their baseline demographics or in clinical variables, including the number of relapses, the need for steroid therapy, or hospitalization (Table 4).

Supportive evidence is also provided by the tolerability data from this study. Although flu-like symptoms are adverse events, they may also serve as indicators of an IFN's biological activity, since they may reflect activation of the immune system. Despite the comparable clinical efficacy of Avonex and Jumtab with respect to conventional parameters, including annual relapse rate, one of the notable findings of the MATRIX study was that significantly fewer patients reported flu-like symptoms on Jumtab than on Avonex. These data suggest reduced bioavailability of the biosimilar. The basis for this possible reduction in IFN beta-1a bioactivity has not been established, but it cannot readily be attributed to the presence of NAbs or reduced patient compliance.

The limitations of this study - due to the low patient recruitment, the non-randomized study design, and the retrospective nature of the analysis - make it impossible to reach solid conclusions about any substantial efficacy differences between Avonex and Jumtab. For example, because relapse-associated outcomes were assessed retrospectively based on cumulative data from 1 to 3 years prior to study enrollment, information regarding the specific time frame in which each relapse occurred was not available and calculation of an annualized relapse rate was not possible. 
Thus, the treatment differences identified in this study require confirmation in a larger prospective study that rigorously compares both the safety and the efficacy of Avonex and IFN beta-1a biosimilars. However, the data presented here provide preliminary evidence that the activity and possible efficacy of biosimilar therapies cannot be assumed to match those of the reference molecule and support the argument that switching patients from a parent formulation to a biosimilar product may have clinical consequences. ${ }^{20}$

The rationale for requiring clinical trials of biosimilars prior to regulatory review is that, given the complexity of these biologic compounds, variations in manufacturing might lead to small variations in the protein that will produce differences in clinical efficacy. For example, the biosimilar IFN beta-1a generated in Chinese hamster ovary cells (Biferonex) was rejected by the European Committee for Medicinal Products for Human Use because of differences between the active molecule in Biferonex and that found in European Medicines Agency (EMA)-approved IFN beta-containing medicines. ${ }^{21}$ Consistent with this finding, biosimilar IFN beta-1a products in general, including Jumtab, have been reported to vary considerably in their biological potency, with lower activity related to, among other factors, the presence of higher-molecular-weight aggregates of IFN beta- $1 \mathrm{a}^{3}{ }^{3}$ There are also reports of substantial variability in the chemical composition of batches of the same biosimilar IFN beta-1 products over time, and this variability might also contribute to the variable clinical efficacy seen here. ${ }^{3}$

\section{Conclusion}

These studies and the data presented here highlight the need for physicians seeking reliable clinical effects to ensure that the specific formulation their patients receive remains consistent. As regulatory guidelines for biosimilar development continue to evolve, ${ }^{11}$ these findings indicate a strong basis, particularly in the European Union and North American countries, for strict regulation in the use of biosimilars to ensure that patients receive effective treatment.

\section{Acknowledgments}

Biogen provided funding for editorial support in the development of this paper. Kristine Zerkowski and Anne Williamson of Infusion Communications wrote the first draft of the manuscript based on input from authors, and Joshua Safran of Infusion Communications copyedited and styled the manuscript per journal requirements. Biogen participated in the design of the study; in the collection, analysis, and interpretation of data; in the writing of the report; and in the decision to submit the article for publication. The MATRIX Investigator Group includes the following individuals: Carlos Cuevas (Instituto Mexicano del Seguro Social, Mexico City, Mexico), Francisco Flores-Ramírez (Hospital Regional ISSSTE Monterrey, Monterrey, Mexico), Miguel Macías-Islas (Universidad de Guadalajara, Guadalajara, Mexico), Sergio Sauri-Suárez (Centro Medico Nacional 20 de Noviembre, Mexico City, Mexico), Jose Manuel Aleman Pedroza (Universidad Autónoma de Guadalajara, Guadalajara, Mexico), Eduardo Duriez Sotelo (Universidad de Monterrey, Monterrey, Mexico), Maria de la Luz Villalpando Gueich (Hospital Angeles Leon, Leon, Mexico), Raul Arcega Revilla (Clinica Neurologica, Puebla, Mexico), Leonardo Llamas Lopez (Hospital Regional ISSSTE Dr Valentín Gómez Farías, Guadalajara, Mexico), Ernesto Ojeda (Universidad del Rosario, Bogota, Colombia), and Pablo Lopez (Neurologos Clinicos Asociados Cia., Ltda, Bogota, Colombia). The authors had full editorial control of the paper and provided their final approval of all content. These results were presented in part at the 28th Congress of the European Committee for Treatment and Research in Multiple Sclerosis (abstract published in Multiple Sclerosis Journal: http://msj.sagepub.com/content/18/4 suppl.toc) and the 11 th International Congress of Neuroimmunology (abstract published in Journal of Neuroimmunology: http:// www.jni-journal.com/article/S0165-5728(12)00304-9/ abstract) as poster presentations. The actual paper, however, has never been published.

\section{Disclosure}

This work was supported by Biogen (study number MEXAVX-12-10324). Carlos Cuevas, Francisco Flores-Ramírez, Miguel Macías-Islas, and Sergio Sauri-Suárez have nothing to disclose. Florian Deisenhammer has participated in meetings sponsored by or received honoraria for acting as an advisor/ speaker for Bayer Healthcare, Biogen, Genzyme-Sanofi, Merck, Novartis Pharma, and Teva-Ratiopharm; his institution has received financial support for participation in randomized controlled trials from Bayer Schering Pharma, Biogen, Merck Serono, and Teva Pharmaceuticals. Xiaojun You and Bjørn Sperling are employees of Biogen. Mariano Scolnik and Regine Buffels were employees of Biogen at the time of this analysis. The authors report no other conflicts of interest in this work.

\section{References}

1. Jacobs LD, Cookfair DL, Rudick RA, et al. Intramuscular interferon beta-1a for disease progression in relapsing multiple sclerosis. The Multiple Sclerosis Collaborative Research Group (MSCRG). Ann Neurol. 1996;39(3):285-294. 
2. PRISMS (Prevention of Relapses and Disability by Interferon beta-1a Subcutaneously in Multiple Sclerosis) Study Group. Randomised double-blind placebo-controlled study of interferon beta-1a in relapsing/remitting multiple sclerosis. Lancet. 1998;352(9139):1498-1504. [published correction appears in Lancet. 1999;353(9153):678].

3. Meager A, Dolman C, Dilger P, et al. An assessment of biological potency and molecular characteristics of different innovator and noninnovator interferon-beta products. J Interferon Cytokine Res. 2011; 31(4):383-392.

4. Reingold SC, Steiner JP, Polman CH, et al. The challenge of follow-on biologics for treatment of multiple sclerosis. Neurology. 2009;73(7): 552-559.

5. Rivera VM. The challenge of follow-on biologics for treatment of multiple sclerosis. Neurology. 2010;74(10):864.

6. Weise M, Bielsky MC, De SK, et al. Biosimilars-why terminology matters. Nat Biotechnol. 2011;29(8):690-693.

7. Deisenhammer F. Neutralizing antibodies to interferon-beta and other immunological treatments for multiple sclerosis: prevalence and impact on outcomes. CNS Drugs. 2009;23(5):379-396.

8. Malucchi S, Gilli F, Caldano M, et al. One-year evaluation of factors affecting the biological activity of interferon beta in multiple sclerosis patients. J Neurol. 2011;258(5):895-903.

9. Vartanian T, Solberg SP, Rice G. Impact of neutralizing antibodies on the clinical efficacy of interferon beta in multiple sclerosis. $J$ Neurol. 2004;251(Suppl 2):II25-II30.

10. Balabanov P, Haas M, Elferink A, Bakchine S, Broich K. Addressing the regulatory and scientific challenges in multiple sclerosis - a statement from the EU regulators. Mult Scler. 2014;20(10):1282-1287.

11. European Medicines Agency. Guideline on similar biological medicinal products containing interferon beta. Available from: http://www. ema.europa.eu/docs/en_GB/_library/Scientific_guideline/2013/03/ WC500139622.pdf. Accessed January 5, 2015.
12. Scagnolari C, Bellomi F, Trombetti S, et al. Expression of biomarkers of interferon type I in patients suffering from chronic diseases. Clin Exp Immunol. 2007;147(2):270-276.

13. Murr C, Widner B, Wirleitner B, Fuchs D. Neopterin as a marker for immune system activation. Curr Drug Metab. 2002;3(2):175-187.

14. Casoni F, Merelli E, Bedin R, Sola P, Bertolotto A, Faglioni P. Is serum neopterin level a marker of responsiveness to interferon beta-1a therapy in multiple sclerosis? Acta Neurol Scand. 2004;109(1):61-65.

15. Avonex (interferon beta-1a) injection, for intramuscular injection [prescribing information]. Cambridge, MA: Biogen; 2014.

16. Bertolotto A, Malucchi S, Sala A, et al. Differential effects of three interferon betas on neutralising antibodies in patients with multiple sclerosis: a follow up study in an independent laboratory. $J$ Neurol Neurosurg Psychiatry. 2002;73(2):148-153.

17. Grossberg SE, Oger J, Grossberg LD, Gehchan A, Klein JP. Frequency and magnitude of interferon beta neutralizing antibodies in the evaluation of interferon beta immunogenicity in patients with multiple sclerosis. J Interferon Cytokine Res. 2011;31(3):337-344.

18. Lam R, Farrell R, Aziz T, et al. Validating parameters of a luciferase reporter gene assay to measure neutralizing antibodies to IFNbeta in multiple sclerosis patients. J Immunol Methods. 2008;336(2):113-118.

19. Werner ER, Bichler A, Daxenbichler G, et al. Determination of neopterin in serum and urine. Clin Chem. 1987;33(1):62-66.

20. Kappos L, Clanet M, Sandberg-Wollheim M, et al; European Interferon Beta-1a IM Dose-Comparison Study Investigators. Neutralizing antibodies and efficacy of interferon beta-1a: a 4-year controlled study. Neurology. 2005;65(1):40-47.

21. European Medicines Agency. Questions and answers on the withdrawal of the marketing authorisation application for Biferonex (interferon beta-1a). Available from: http://www.ema.europa.eu/docs/ en_GB/document_library/Medicine_QA/2010/01/WC500061395.pdf. Accessed January 5, 2015.
Biosimilars

\section{Publish your work in this journal}

Biosimilars is an international, peer-reviewed, open access journal focusing on the manufacture, development and medicinal use of biopharmaceutical compounds considered similar to an innovator agent. Specific topics covered in the journal include: Regulatory issues and pathways; manufacturing processes; chemical composition and

\section{Dovepress}

structure; quality and purity; patent issues; bioequivalence and interchangeability; clinical efficacy data; patient perspectives. The manuscript management system is completely online and includes a very quick and fair peer-review system. Visit http://www.dovepress.com/ testimonials.php to read real quotes from published authors. 